\title{
Prevention of Diabetic Glomerulopathy in Streptozotocin Diabetic Rats by Insulin Treatment
}

\author{
Glomerular Basement Membrane Thickness
}

\section{R. Rasch}

Second University Clinic of Internal Medicine, University Institute of Pathology, Århus Kommunehospital and Department of Cell Biology, Institute of Anatomy, University of Århus, Århus, Denmark

\begin{abstract}
Summary. Glomerular basement membrane thickness (GBMT) has been measured in streptozotocin diabetic rats treated with insulin. The study included 3 groups of 8 rats each: 1) a 'well-controlled' group of diabetic rats under insulin treatment with a plasma glucose level reasonable close to normal values, 2) a 'poorly-controlled' group also under insulin trcatment with constant high plasma glucose values, and 3 ) an age and weight matched non-diabetic control group. After 6 months of diabetes, GBMT was measured applying an intercept method on 3 glomerular cross sections from each of the 24 animals. The measurements showed that mean GBMT was 132.2. $\mathrm{nm}$ in the non-diabetic control rats and $131.6 \mathrm{~nm}$ in the 'well-controlled' diabetic rats. In the 'poorly-controlled' group the mean GBMT was $140.4 \mathrm{~nm}$, i.e. statistically significantly increased when compared to each of the two other groups, $2 p=0.022$ and 0.012 respectively.
\end{abstract}

The results demonstrate that good blood glucose control in rats preserves normal GBMT.

Key words: Glomerular basement membrane, streptozotocin diabetes, glucose control in rats, diabetic glomerulopathy, stercology, membrane thickness.

There is evidence suggesting that good control of blood glucose level inhibits the development of diabetic microangiopathy, but proof is lacking.

In an earlier report, dealing with a 6 months study of an animal model with nearly complete control of plasma glucose [27] it was shown that good control prevents the development of large kidneys and large glomeruli in diabetic rats [29]. The present study deals with determinations of GBMT in those animals used for the study of renal and glomerular volume.

\section{Materials and Methods}

Female Wistar rats were used for the experiments. They were 84 t 12 (SI) days old at the start of the experiment with a mean body weight of $188+9 \mathrm{~g}$. Streptozotocin $(90 \mathrm{mg} / \mathrm{kg})$ was administered intravenously and two days later insulin treatment was started in the rats that had developed gross glycosuria and ketonuria. During the 6 months period a special, heat treated, noncommercial, very long acting Ultralente insulin (MC,ox, pH 5.5) [27, 31] was administered daily.

Diabetic animals were separated into two groups: In the first good control of plasma glucose was intended and this group is henceforth referred to as the 'well-controlled' group. In the second group no attempt was made to achieve good control and these animals are referred to as the 'poorly-controlled' group. A third group consisted of age and weight matched non-diabetic control rats. There were originally 10 controls and 11 animals in each of the two other groups. One 'poorly-controlled' animal died after 2 months of diabetes.

The animals were kept in metabolic cages with free access to water and a vitamin feed mixture (65\% carbohydrate, $30 \%$ protein and $5 \%$ fat). Urine volume was measured every day and glycosuria and ketonuria determined qualitatively with Clinistix ${ }^{R}$ and Ketostix $^{R}$, (Ames Company Inc.).

In the 'well-controlled' group blood was drawn from the tip of the tail on 5 days a week between 8 and 9 a.m. Plasma glucose was measured with Dextrostix ${ }^{\mathrm{R}}$ and a Reflectance Meter (Ames Company Inc.) (17). Insulin was injected subcutaneously in the abdomen and the dose determined by a previously described scheme (27). Below $50 \mathrm{mg} / 100 \mathrm{ml}$ no insulin was administered; between 50 and $150 \mathrm{mg} / 100 \mathrm{ml}$ the insulin dose remained unchanged and only a plasma glucose of more than $150 \mathrm{mg} / 100 \mathrm{ml}$ on 3 consecutive days resulted in an increase in daily insulin dose.

In the 'poorly-controlled' group plasma glucose was measured every 14 days between 8 and 9 a.m. and the same amount of blood as that lost due to regular sampling in the 'well-controlled' group was drawn. The insulin dose was kept as low as possible without the animals developing ketonuria. In the non-diabetic control animals blood glucose was measured every fortnight and the same amount of blood was drawn from these animals as from the 'poorly-controlled' ones.

After 3 and 5 months, plasma glucose concentration was measured in all the diabetic rats 3 and 15 hours after the insulin injection.

Once a month the $24 \mathrm{~h}$ urine volume from 4 consecutive days were collected from the diabetic animals and used for quantitative 


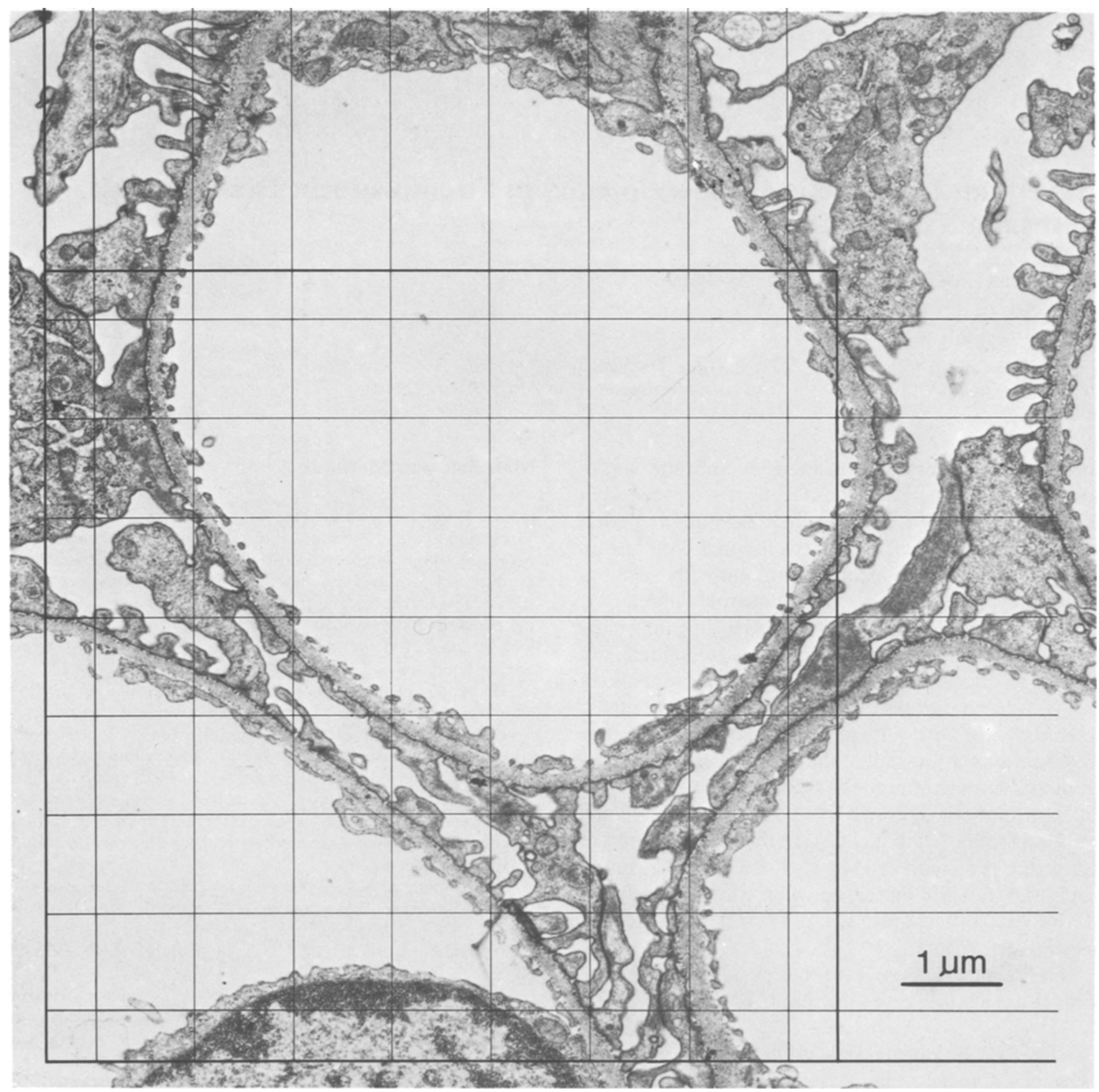

Fig. 1. Reduced electron micrograph with a square grid superposed. Original line distance is $30 \mathrm{~mm}$. $\cdots$ Limit between the basement membrane of the capillary and the mesangial BMLM

urine glucose measurements made with a glucose oxidase method (Glox, KABI): Every third month $24 \mathrm{~h}$ urine volume was measured in the non-diabetic control animals.

After 6 months the animals were anaesthetized with diazepam $(12.5 \mathrm{mg} / \mathrm{kg})$ and pentobarbital $(50 \mathrm{mg} / \mathrm{kg})$. A retrograde perfusion fixation of the left kidney was performed through the aorta under standardized conditions, first with $12 \mathrm{ml}$ of a modified Tyrode solution (containing $3 / 4$ of the normal $\mathrm{NaCl}$ amount) [23] with $1 \%$ glutaraldehyde, then for 10 minutes with the same solution with the addition of $0.5 \%$ Alcian Blue $[26,30]$. The complete Tyrode solution had the following composition: $\mathrm{NaCl} 0.8 \mathrm{~g} / 1, \mathrm{KCl}$ $0.2 \mathrm{~g} / \mathrm{l}, \mathrm{CaCl}_{2} 0.2 \mathrm{~g} / \mathrm{l}, \mathrm{MgCl}_{2} 6 \mathrm{H}_{2} \mathrm{O} 0.1 \mathrm{~g} / \mathrm{l}, \mathrm{NaHCO}_{3} 1.0 \mathrm{~g} / \mathrm{l}$, $\mathrm{NaH}_{2} \mathrm{PO}_{4} \mathrm{H}_{2} \mathrm{O} 0.05 \mathrm{~g} / 1$, and glucose $1.0 \mathrm{~g} / 1$. The osmolality of the final solution was measured before the perfusions and found to be within a narrow range $(370-376 \mathrm{mosm} / \mathrm{kg})$. The $\mathrm{pH}$ was always 7.1 (non-adjusted) when measured before perfusions. All kidneys bleached immediately after the glutaraldehyde perfusion had started and became blue within 30 seconds of the start of the Alcian Blue perfusion. The perfusion was also evaluated with light microscopy on unstained paraffin sections of whole kidneys. Alcian Blue stains glomeruli more heavily than the surrounding tissue $[26,30]$. Perfusions were considered good if all but few glomeruli were heavily stained. Alcian Blue was added for electron microscopic histochemical studies of the mesangial regions but not for studies on the GBM [30].

Tissue for electron microscopy was cut from the lateral border of the left kidney at the level of the renal artery. Small blocks from the superficial cortex were post-fixed in osmium, dehydrated in 
Table 1. Results from the 6 months experiment with groups of rats in 2 different types of blood glucose control

\begin{tabular}{|c|c|c|c|c|}
\hline & & Non-diabetic & $\begin{array}{l}\text { 'Well-controlled } \\
\text { diabetic' }\end{array}$ & $\begin{array}{l}\text { 'Poorly-controlled } \\
\text { diabetic' }\end{array}$ \\
\hline Number of animals & & 8 & 8 & 8 \\
\hline $\begin{array}{l}\text { Body weight at } \\
\text { start of experiment } \\
\text { Body weight after }\end{array}$ & (g) & $190 \pm 9$ & $185 \pm 8$ & $190 \pm 9$ \\
\hline 6 months & $(\mathrm{g})$ & $310 \pm 28$ & $320 \pm 27$ & $222 \pm 28$ \\
\hline $\begin{array}{l}\text { Amount of insulin/ } \\
\text { day } \\
\text { Plasma glucose }\end{array}$ & $(\mathrm{U} / \mathrm{kg})$ & 0 & $7.7 \pm 2.2$ & $1.5 \pm 0.2$ \\
\hline 8 a.m. & $(\mathrm{mg}$ per $100 \mathrm{ml})$ & $87 \pm 9$ & $182 \pm 20$ & $452 \pm 41$ \\
\hline 11 a.m. & & - & $120 \pm 47$ & $338 \pm 71$ \\
\hline 11 p.m. & & - & $95 \pm 35$ & $555 \pm 86$ \\
\hline $\begin{array}{l}24 \text { hours urine volume } \\
\text { Urine glucose per }\end{array}$ & $(\mathrm{ml})$ & $14 \pm 7$ & $18 \pm 6$ & $110 \pm 4$ \\
\hline $\begin{array}{l}\text { Urine glucose per } \\
24 \text { hours }\end{array}$ & (g) & - & $0.19 \pm 0.10$ & $10+2$ \\
\hline GBMT & $(\mathrm{nm})$ & $132.2 \pm 7.2$ & $131.6 \pm 6.7$ & $140.4 \pm 5.6$ \\
\hline
\end{tabular}

Plasma glucose (PG) at 8 a.m. = Mean PG for the whole period. $n=123$ PG measurements per animal in the 'well-controlled' group. In the 'poorly-controlled' group and in the group of non-diabetic controls, $n=12 \mathrm{PG}$ measurements per animal. In the calculations of mean per group $n=8$. PG at 11 a.m. and p.m. $n=2$ measurements per animal. Mean per group $n=8$. Results are given as mean \pm SD

acetone, embedded in Vestopal and stained with uranyl acetate and lead citrate. Four kidneys were not well-perfused, two from the 'poorly-controlled' group and one from each of the two other groups. These kidneys were not used in the experiment. Among the rest of the kidneys 8 were randomly selected from each group.

Three blocks were cut from each of these kidneys. From each of these blocks semi-thin sections were prepared and one complete glomerular profile was selected for electron microscopy after a certain scheme and irrespective of size. Only sections from the central part of the glomerulus were used to prepare the thin sections. This was ascertained by comparing the first and the last section of a series after a fixed number of cuttings with the ultramicrotome. The thin sections were contrasted with uranyl acetate and lead citrate.

From the cross sections, areas to be photographed were selected systematically and independent of the glomerular structures, stopping the specimen stage at preselected intervals marked out at the handles. An average of 40 fields, corresponding to $1 / 3$ of the tuft area, were photographed on each cross-section with a Philips EM 200. On each film a carbon grating replica (line density 11024 lines $/ \mathrm{cm}$ ) was photographed. From these the final magnification of $28359 \mathrm{X}$ was calculated.

The measurements of the glomerular basement membrane thickness were performed on the basement membrane of the capillary. The delineation towards the basement membrane-like material of the mesangial regions was placed where the endothelial and the epithelial side of the basement membrane run parallel (see Fig. 1). The delineation was made perpendicular to both sides. A square grid, shown in Fig. 1, was used for obtaining random intercepts between the peripheral basement membrane and the test lines. Employing a ruler the length of each intercept was classified. About 850 intercept lengths were measured per animal. All measurements were performed blindly, in random sequence and by the same technician. In each kidney GBMT was calculated from the measured distribution of intercepts. All measured intercepts from the three glomerular cross sections from one animal were summed and used for the calculation of the harmonic mean basement membrane thickness ( $\mathrm{Th}$ ) with the equation $\mathrm{Th}=2 / 3 \mathrm{lh}$, where $\mathrm{lh}$ is the harmonic mean intercept length [12]. The harmonic mean was chosen since it has minimal variance and bias compared to the commonly used arithmetic value [12].

\section{Statistical Methods}

Harmonic mean glomerular basement membrane thickness (Th) was calculated for each animal and Student's t-test for independent samples was used for comparisons of arithmetic mean values of the experimental groups.

The intra-individual, inter-glomerular variation $\left(\mathrm{SD}_{\mathrm{g}}\right)$ of the harmonic mean thickness was calculated for each 3 groups of animals by

$\mathrm{SD}_{\mathrm{g}}=\sqrt{\frac{\sum\left(\mathrm{SD}_{1}^{2} \times(3-1)\right.}{\mathrm{n} \times(3-1)}}$

where $\mathrm{SD}_{\mathrm{i}}$ is the inter-glomerular variation in one animal based on 3 glomerular cross sections. Due to e.g. the polarity of the glomerular tuft in three dimensions and the spatial restrictions on the orientation distribution of the basement membrane, the calculated $\mathrm{SD}_{\mathrm{g}}$ represents a small overestimation of the true interglomerular variation [41].

\section{Results}

The general condition of the animals is detailed in Table 1. The animals in the 'well-controlled' group gained weight at the same rate as the non-diabetic controls, whereas the weight gain of the 'poorly-controlled' diabetic rats was considerably less.

Urine volume in the 'well-controlled' group of diabetic animals was a little higher than that of the non-diabetic control animals. The 'well-controlled' group had low intermittent glycosuria. Mean glucose excretion per day was $0.19 \pm 0.10 \mathrm{~g}$ and on $62 \pm$ $11 \%$ of all days the animals showed no glycosuria. The 'poorly-controlled' animals were never without glycosuria and mean urine glucose excretion was 10 $\pm 2 \mathrm{~g}$ per day. In the course of the experiment two 
animals showed slight ketonuria on one occasion, but otherwise all the other animals were without ketonuria throughout the experiment.

Mean 8 a.m. pre-insulin, non-fasting plasma glucose levels are nearly always the highest blood glucose during the day [27]. In the 'well-controlled' group of diabetic rats it was $182 \pm 20 \mathrm{mg} / 100 \mathrm{ml}$ compared to $89 \pm 9 \mathrm{mg} / 100 \mathrm{ml}$ in normal rats. Plasma glucose, however, fell to normal values by 11 a.m. and were still normal at 11 p.m.

The average daily insulin dose administered was $7.7 \pm 2.2 \mathrm{U} / \mathrm{kg}$ in the 'well-controlled' group and 1.5 $\pm 0.2 \mathrm{U} / \mathrm{kg}$ in the 'poorly-controlled' group.

Measurements of the GBMT showed a mean Th in the non-diabetic control group of $132.2 \pm$ 7.2 (SD) nm. In the 'well-controlled' diabetic group it was $131.6 \pm 6.7 \mathrm{~nm}$, whereas in the 'poorly-controlled' group it was $140.4 \pm 5.6 \mathrm{~nm}$. The $6 \%$

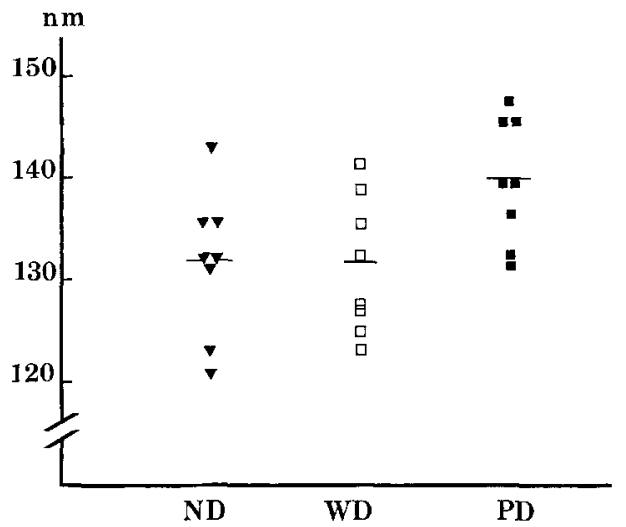

Fig. 2. Glomerular basement membrane thickness (Th) in three groups of rats. ND: Non-diabetic rats - WD: 'Well-controlled' diabetic rats - PD; 'Poorly-controlled' diabetic rats increase in GBMT in the 'poorly-controlled' group is statistically significant when compared to the 'wellcontrolled' diabetic rats $(2 \mathrm{p}=0.012)$ and to the non-diabetic control rats $(2 \mathrm{p}=0.022)$, Figure 2 and Table 1.

Figure 3 shows on a linear scale the cumulative frequency of intercept lengths from three different animals, one from each group. This illustration shows the smaller number of short intercepts measured in the 'poorly-controlled' group compared to the two other groups. From measured intercepts like these the Th was calculated.

The inter-glomerular variation in the non-diabetic controls was 4.7 , in the 'well-controlled' diabetic group 5.0 and in the 'poorly-controlled' group $5.4 \mathrm{~nm}$.

\section{Discussion}

In the present study it has been shown that a plasma glucose level fairly close to normal throughout a 6 months period preserves normal GBMT in streptozotocin diabetic rats, whereas rats with constantly high plasma glucose develop thicker basement membranes. This is of particular interest because the changes occur in rats with experimental, as opposed to genetic, diabetes and because the temporal pattern of development of these changes is very similar to those occurring in the glomeruli of human diabetes $(25,39)$. The ultrastructure of the glomerular basement membrane of the capillary has been studied before with a quantitative electron microscopic technique in human diabetics and in experimentally diabetic animals. In humans the glomerular basement

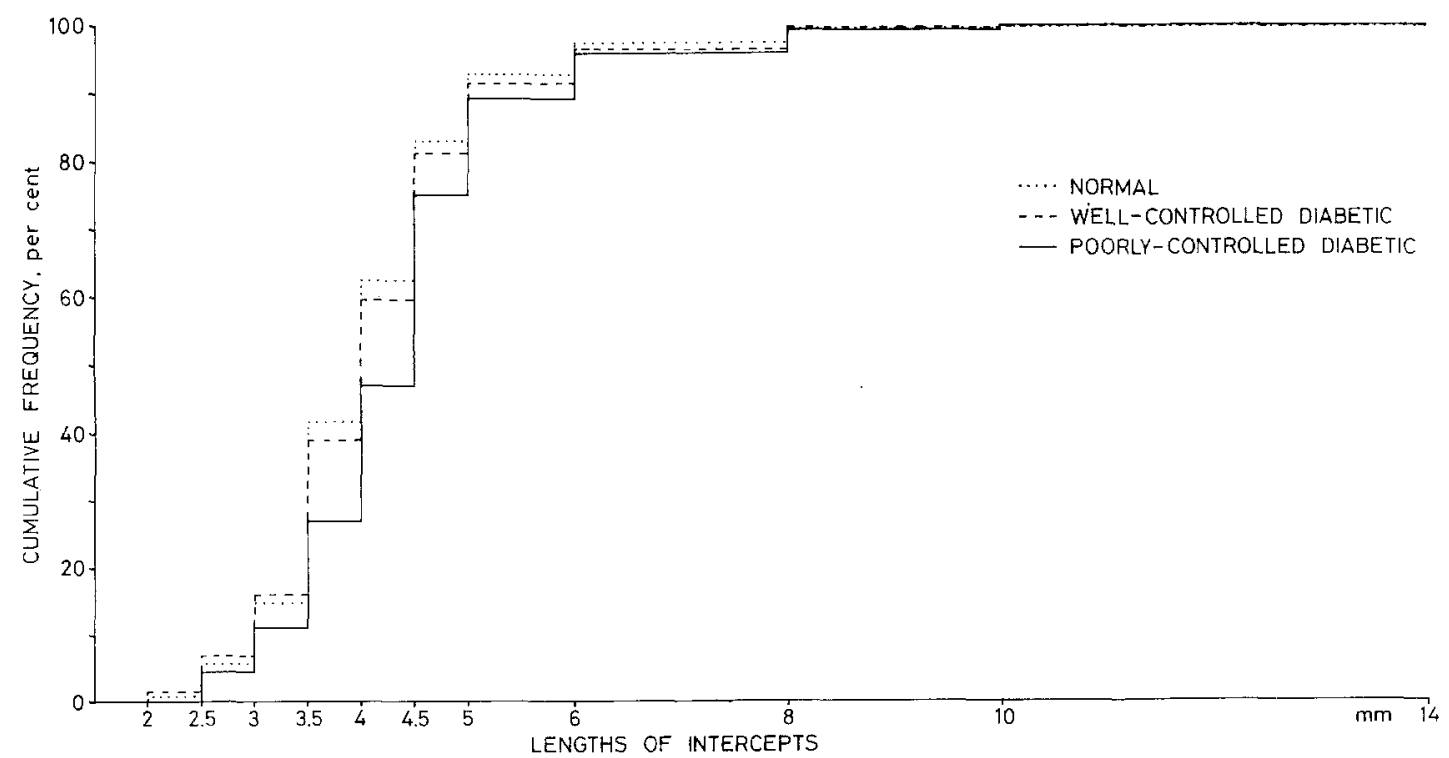

Fig. 3. Cumulative frequency of intercept lenghts from one animal from each group. The scale is in classes which are almost equidistant in the reciprocal scale 
membrane is thicker in diabetics compared to nondiabetic controls [40] and the glomerular basement membrane increases in thickness with increasing duration of diabetes [40]. In the experimentally diabetic rat the glomerular basement membrane is thicker than in non-diabetic controls $[7,10,14]$ and the basement membrane thickening increases with the duration of diabetes. [7]

Hägg studied the effect of insulin on GBMT in diabetic rats. The GBMT was measured on electron micrographs after 12 months of diabetes in animals that had been treated with insulin for the last 3 months [16]. No effect of the insulin treatment could be seen on the GBMT, most likely because the treatment period was much shorter than the period with untreated diabetes. It is of interest, however, that a positive relation between GBMT and mean diuresis was found in a group of untreated diabetic rats [14].

In a recent paper by Fox et al. [10] GBMT was reported to be positively related to blood glucose. The regression analyses performed, however, include the non-diabetic control animals. It is particularly noteworthy that in their study no correlation is shown between blood glucose and GBMT within the diabetic groups of animals in various treatments [11, 28]. In the study a correction of GBMT for body weight was also performed, although the reasons for this seem unclear. In the calculated relation between GBMT and blood glucose the two hour post-insulin blood glucose level was used. However, because insulin treated rats show extensive blood glucose fluctuations throughout the day $[16,27]$ more determinations of blood glucose are required on many more days [28].

Many other light-and electron microscopic studies not including exact basement membrane measurements have shown that morphological changes in renal structures occur in animals with experimental diabetes similar to those seen in human diabetes $[1,7,8,10,13,14,24,25,35,38,39]$.

Light microscopic mesangial changes have shown regression or at least lack of progression in diabetic rats subjected to pancreatic islet transplantation resulting in total normalization of blood glucose [21, 22]. Immunohistochemistry of the glomerulus from the diabetic rat has shown a deposit of immunoglobulin and complement after 1-4 months of diabetes [15, $20]$ and these changes are reversible after normalization of blood glucose by pancreatic islet transplantation $[21,22]$, kidney transplantation into normal animals from diabetic ones [19] or by insulin treatment [16]. The mechanism which caused the IgG deposits and its possible relationship to glomerular basement membrane thickening remains to be clarified.

Disagreement exists as to the nature and existence of biochemical changes in kidneys from diabetic patients and rats with experimental diabetes. Beisswenger and Spiro $[2,3]$ have reported a change in GBM chemical composition in diabetic patients, whereas Westberg [37] and Kefalides [18] have failed to confirm this. In diabetic rats Spiro has found an increase in renal cortical glucosyltransferase [33] but Beisswenger did not find any difference in the production rate of hydroxylysine in rats [4]. The effect of insulin on the enzyme glucosyltransferase has also been investigated. The level of this enzyme is considered to be related to basement membrane synthesis. It is increased in the alloxan diabetic kidney cortex and normalization takes place when insulin treatment is started early (after one week of diabetes), and not if it is initiated after longer duration of diabetes [33].

Diabetic angiopathy occurs, in various modifications, in most or all the organs of long term diabetic patients. In experimental diabetes a characteristic retinopathy is known to develop in the course of years in the dog. Engerman and Bloodworth [9] showed a complete inhibition of the development of this retinopathy in alloxan diabetic dogs, carefully kept at a relatively normal blood glucose level for 5 years.

The cause of the GBMT in diabetes is still a matter of debate. In the present study a postulated genetic factor [32] can be ruled out. The GBMT cannot be caused by streptozotocin since both groups of diabetic rats were given the same dose of streptozotocin. It cannot be due to insulin or insulin impurities [5] because both diabetic groups were treated with insulin and the group without membrane thickening received the largest dose of insulin (Table 1) $[6,34$, 36].

It must be concluded from the present study that GBMT can in fact occur as a consequence of the metabolic derangement resulting from long-term, insufficient insulin treatment of a diabetic state. With due reservation the results in the present study lend support to the idea that human diabetes ought to be controlled as closely as possible in order to inhibit the development of vascular abnormalities.

Acknowledgements. I am indebted to Dr. J. Schlichtkrull, NOVO,
who provided the special insulin preparation for the experiments.
I am gratefull to Lis Nielsen, Grete Glerup, and Kirsten Ger-
lach for excellent technical assistance.
Supported by grants from: Statens lagevidenskabelige Fors-
kningsråd, Carlsbergfonden, NOVO Fonden, Nordisk Insulinfond,
King Christian den Tiendes Fond.

\section{References}

1. Anjo, A., Couturier, E.: Mesangial changes of the renal glomerulus in long-term diabetic rats. Pathol. Eur. 10, 21-27 (1975)

2. Beisswenger, P. J., Spiro, R. G.: Human glomerular basement membrane: Chemical alteration in diabetes mellitus. Science 168, 596-598 (1970) 
3. Beisswenger, P.J., Spiro, R. G.: Studies on the human glomerular basement membrane. Composition, nature of the carbohydrate units and chemical changes in diabetes mellitus. Diabetes 22, 180-193 (1973)

4. Beisswenger, P. J.: Glomerular basement membrane. Biosynthesis and chemical composition in the streptozotocin diabetic rat. J. Clin. Invest. 58, 844-852 (1976)

5. Berns, A. W., Owens, T. C., Hirata, Y., Blumenthal, H. T.: The pathogenesis of diabetic glomuerulosclerosis. II. A demonstration of insulin-binding capacity of the various histopathological components of the disease by fluorescence microscopy. Diabetes 11, 308-317 (1962)

6. Burkholder, P.M.: Immunohistopathologic study of the localized plasma proteins and fixation of guinea pig complement in renal lesions of diabetic glomerulosclerosis. Diabetes 14, 755-770 (1965)

7. Cameron, D.P., Amherd, M., Leuenberger, P., Orei, L., Stauffacher, W.: Microvascular alterations in cronically streptozotocin diabetic rats. In: Early diabetes. Advances in metabolic disorders. Camerini-Davalos, R. A., Cole, H. S., (Eds), suppl. 2, pp. 257-269. London: Academic Press 1973

8. Ditscherlein, G., Kranz, D., Marx, I., Dena, R.: Elektronmikroskopische Untersuchungen an Rattennieren bei langdauerndem unbehandelten Alloxandiabetes. Exp. Pathol. (Jena) 4, 222-239 (1970)

9. Engerman, R. L., Bloodworth, J. M. B., Nelson, S.: Relationship of microvascular disease in diabetes to metabolic control. Diabetes 26, 760-769 (1977)

10. Fox, C. J., Darby, S. C., Ireland, J. T., Sönksen, P. H.: Blood glucose control and glomerular basement membrane thickening in experimental diabetes. Br. Med. J. 1977 H, 605-607

11. Fox, C. J., Darby, S. C., Sönksen, P. H., Ireland, J. T.: Letter to the Editor. Br. Med. J. 1977 II, 1220

12. Gundersen, H. J. G., Jensen, T. B., Østerby, R.: Distribution of membrane thickness determined by lineal analyses. J. Microsc. 113, 27-43 (1978)

13. Hägg, E.: Renal lesions in rats with long-term alloxan diabetes. Acta Pathol. Microbiol. Scand. [A] 82, 199-210 (1974)

14. Hägg, E.: Glomerular basement membrane thickening in rats with long-term alloxan diabetes. A quantitative electron microscopic study. Acta Pathol. Microbiol. Scand. [A] 82, 211-219 (1974)

15. Hägg, E.: Occurrence of immunoglobulin and complement in the glomeruli of rats with long-term alloxan diabetes. Acta Pathol. Microbiol. Scand. [A] 82, 220-227 (1974)

16. Hägg, E.: Influence of insulin treatment on glomerular changes in rats with long-term alloxan diabetes. Acta Pathol. Microbiol. Scand. [A] 82, 228-234 (1974)

17. Jarrett, R. J., Keen, H., Hardwick, C.: 'Instant' blood sugar measurement using Dextrostix and Reflectance Meter. Diabetes 19, 724-726 (1970)

18. Kefalides, N. A.: Biochemical propertics of human glomerular basement membrane in normal and diabetic kidney. J. Clin. Invest. 53, 403-407 (1974)

19. Lee, C. S., Mauer, S. M., Brown, D. M., Sutherland, D. E. R., Michael, A. E., Najarian, J. S.: Renal transplantation in diabetes mellitus in rats. J. Exp. Med. 139, 793-800 (1974)

20. Mauer, S. M., Michael, A. F., Fish, A. J., Brown, D. M.: Spontaneous immunoglobulin and complement deposition in glomeruli of diabetic rats. Lab. Invest. 27, 488-494 (1972)

21. Mauer, S. M., Sutherland, D. E. R., Steffes, M. W., Leonard, R. J., Najarian, J. S., Michael, A. P., Brown, D. M.: Pancreatic islet transplantation. Effects on the glomerular lesions of experimental diabetes in the rat. Diabetes 23, 748-753 (1974)

22. Mauer, S. M., Steffes, M. W., Sutherland, D. E. R., Najarian, J.S., Michael, A. F., Brown, D. M.: Studies on the rate of regression of the glomerular lesions in diabetic rats treated with pancreatic islet transplantation. Diabetes 24, 280-285 (1975)
23. Maunsbach, A. B.: The influence of different fixatives and fixation methods on the ultrastructure of rat kidney proximal tubule cells. II. Effects of varying osmolity, ionic strength, buffer system and fixative concentration of glutaraldehyde solutions. J. Ultrastruct. Res. 15, 283-309 (1966)

24. Olsen, T. S.: Diabetic glomerulosclerosis: A comparison between human and experimental lesions. Int. Rev. Exp. Pathol. 7, 271-304 (1969)

25. Olsen, T. S., Orskov, H., Lundbæk, K.: Kidney lesions in rats with severe long-term alloxan diabetes. II. Histochemical studies. Comparison with human diabetic glomerular lesions. Acta Pathol. Microbiol. Scand. [A] 66, 1-12 (1966)

26. Rasch, R., Fenger, C.: A structural abnormality of the mesangial basement membrane material in diabetic rat glomeruli. J. Ultrastruct. Res. 54, 487 (1976)

27. Rasch, R.: Control of blood glucose levels in streptozotocin diabetic rat using a long acting heat treated insulin. Diabetologia 16, 185-190 (1979)

28. Rasch, R., Gundersen, H. J. G.: Hyperglycaemia and complications of diabetes. Br. Med. J. 1977 II, 1220

29. Rasch, R.: Prevention of diabetic glomerulopathy in streptozotocin diabetic rats by insulin treatment. Kidney size and glomerular volume. Diabetologia 16, 125-128 (1979)

30. Rasch, R.: Prevention of diabetic glomerulopathy by careful insulin treatment, experimental studies of the mesangial regions. Diabetologia 15, 264 (1978)

31. Schlichtkrull, J.: Insulin Crystals, Thesis, p. 97. Copenhagen: Ejnar Munksgaard Publishers 1958

32. Siperstein, M. D., Unger, R. H., Madison, L. L.: Studies of muscle capillary basement membranes in normal subjects, diabetic and prediabetic patients. J. Clin. Invest. 47, 1973-1999 (1968)

33. Spiro, R. G., Spiro, M. J.: Effect of diabetes on the biosynthesis of the renal glomerular basement membrane. Studies on the glucosyltransferase. Diabetes 20, 641-648 (1971)

34. Thomson, O.F.: Studies of diabetic glomerulosclerosis using an immunofluorescent technique. Acta Pathol. Microbiol. Scand. [A] 80, 193-200 (1972)

35. Weil, R., Nozawa, M., Koss, M., Weber, C., Reemtsma, K., McIntosh, R.: The kidney in streptozotocin diabetic rats. Arch. Pathol. Lab. Med. 100, 37-49 (1976)

36. Westberg, N. G., Michael, A.F.: Immunohistopathology of diabetic glomerulosclerosis. Diabetes 21, 163-174 (1972)

37. Westberg, N. G., Michael, A. F.: Human glomerular basement membrane: Chemical composition in diabetes mellitus. Acta Med. Scand. 194, 39-47 (1973)

38. Ørskov, H., Olsen, T. S., Nielsen, K., Rafaelsen, O. J., Lundbrk, K.: Kidney lesions in rats with severe longterm alloxan diabetes. I. Influence of age, alloxan damage and insulin administration. Diabetologia 1, 172-179 (1965)

39. Østerby, R., Lundbæk, K., Olsen, T.S., Ørskov, H.: Kidney lesions in rats with severe long-term alloxan diabetes. III. Glomerular ultrastructure. Lab. Invest. 17, 675-692 (1967)

40. Østerby, R.: Morphometric studies of the periferal glomerular basement membrane in early juvenile diabetes. I. Development of initial basement membrane thickening. Diabetologia 8, 84-92 (1972)

41. Østerby, R., Gundersen, H. J.: Sampling problems in the kidney. In: Lecture notes in biomathematics, Vol. 23. Miles, R. E., Serra, J. (Eds.), pp. 185-191. Berlin, Heidelberg, New York: Springer 1978

Received: February 27, 1978,

and in revised form: October 17,1978

Dr. R. Rasch

Department of Cell Biology

Institute of Anatomy

University of Århus

DK-8000 Århus C, Denmark 